\title{
Spatio-temporal analysis of sub-hourly rainfall over Mumbai, India: Is statistical forecasting futile?
}

\author{
Jitendra Singh ${ }^{1}$, Sheeba Sekharan ${ }^{1}$, Subhankar Karmakar ${ }^{1,3,4, *}$, \\ Subimal Ghosh ${ }^{2,3,4}$, P E Zope ${ }^{2}$ and T I Eldho ${ }^{2,3}$ \\ ${ }^{1}$ Centre for Environmental Science and Engineering, Indian Institute of Technology Bombay, \\ Powai, Mumbai 400 076, India. \\ ${ }^{2}$ Department of Civil Engineering, Indian Institute of Technology Bombay, Powai, Mumbai 400 076, India. \\ ${ }^{3}$ Interdisciplinary Program in Climate Studies, Indian Institute of Technology Bombay, \\ Powai, Mumbai 400 076, India. \\ ${ }^{4}$ Centre for Urban Science and Engineering, Indian Institute of Technology Bombay, \\ Powai, Mumbai 400 076, India. \\ *Corresponding author.e-mail: skarmakar@iitb.ac.in
}

\begin{abstract}
Mumbai, the commercial and financial capital of India, experiences incessant annual rain episodes, mainly attributable to erratic rainfall pattern during monsoons and urban heat-island effect due to escalating urbanization, leading to increasing vulnerability to frequent flooding. After the infamous episode of 2005 Mumbai torrential rains when only two rain gauging stations existed, the governing civic body, the Municipal Corporation of Greater Mumbai (MCGM) came forward with an initiative to install 26 automatic weather stations (AWS) in June 2006 (MCGM 2007), which later increased to 60 AWS. A comprehensive statistical analysis to understand the spatio-temporal pattern of rainfall over Mumbai or any other coastal city in India has never been attempted earlier. In the current study, a thorough analysis of available rainfall data for 2006-2014 from these stations was performed; the 2013-2014 subhourly data from 26 AWS was found useful for further analyses due to their consistency and continuity. Correlogram cloud indicated no pattern of significant correlation when we considered the closest to the farthest gauging station from the base station; this impression was also supported by the semivariogram plots. Gini index values, a statistical measure of temporal non-uniformity, were found above 0.8 in visible majority showing an increasing trend in most gauging stations; this sufficiently led us to conclude that inconsistency in daily rainfall was gradually increasing with progress in monsoon. Interestingly, night rainfall was lesser compared to daytime rainfall. The pattern-less high spatio-temporal variation observed in Mumbai rainfall data signifies the futility of independently applying advanced statistical techniques, and thus calls for simultaneous inclusion of physics-centred models such as different meso-scale numerical weather prediction systems, particularly the Weather Research and Forecasting (WRF) model.
\end{abstract}

\section{Introduction}

A large segment of the thriving population across the world resides in coastal cities due to strategic advantages such as tropical climate and convenient trade opportunities through sea-routes; for instance, most populous and economically-developed megacities such as Tokyo, Jakarta, Seoul and many

Keywords. Correlogram; Gini index; Mumbai rainfall; rainfall forecasting; semivariogram; spatio-temporal analysis; sub-hourly data. 
others are located on coastlines. Coastal cities pay the price for the same with increasingly erratic rainfall and associated exposure to flood risk. Out of the 20 major coastal cities around the world, four Indian cities have been identified to be the most vulnerable to losses due to flooding; Mumbai has been ranked 5th in 2005 in 'average annual losses risk' due to flood with respect to local GDP, and is expected to be 2nd in 2050 based on the scenario assuming socio-economic change and optimistic sea-level rise if adaptation policy maintains present flood probability (Hallegatte et al. 2013). A commonly observed characteristic of rainfall in such cities is its high spatial variability. Moreover, rainfall is an inherently dynamic environmental process, and hence understanding its temporal variability is also inevitable. Likewise, Mumbai, a megacity situated on the west coastline of India in the state of Maharashtra, is the most densely inhabited metropolis of the country at 12.4 million as per the 2011 census (Phatak and Hukku 2015). It, being the commercial and financial capital of India, is home to important financial institutions such as the Reserve Bank of India (RBI), the National Stock Exchange of India (NSE), the Bombay Stock Exchange (BSE), and various national and multinational corporations (Sherly et al. 2015a). This city is undergoing unprecedented expansion, in terms of infrastructure and urbanisation; consequently making it highly vulnerable to natural/man-made disasters. Mumbai experiences severe flood almost every year due to incessant rain during the southwest monsoon period of JuneJuly-August-September (JJAS) along with concurrent high tidal events. Monsoon in Mumbai is heavily influenced by the Western Ghats (Sahyadri mountains) running through the states of Maharashtra, Karnataka and Kerala. Strong winds of southwest monsoon (Somali Jet) carrying moisture laden monsoon air from the Arabian Sea are orographically lifted when they collide with the Western Ghats (Jenamani et al. 2006). Rainfall in the Western Ghats is also a result of a number of phenomena such as the presence of a northwardmoving meso-scale offshore vortex over the northeast Arabian Sea, north-westward movement of low-pressure systems from the Bay of Bengal along the monsoon trough (Lei et al. 2008). It was also observed by Rana et al. (2012) that the southwest monsoon in Mumbai is inversely related with Indian Ocean dipole, El Nino-Southern Oscillation along with east Atlantic pattern.

Several studies found the above-mentioned features to be responsible for the formation of extreme rainfall events in Mumbai, subsequently leading to flooding (Jenamani et al. 2006; Kumar et al. 2008; Lei et al. 2008; Rana et al. 2012). The most unprecedentedly catastrophic and, hence, the most researched extreme rainfall event of Mumbai occurred on 26th July 2005. This heavily localised rainfall event recorded in different areas of Mumbai over the 24-hour period clearly displayed high spatial variability: Santa Cruz $-94 \mathrm{~cm}$, Bhandup -81 $\mathrm{cm}$, Dharavi $-49 \mathrm{~cm}$, Vihar lake $-104 \mathrm{~cm}$, Malabar Hill $-7 \mathrm{~cm}$ and Colaba $-7 \mathrm{~cm}$ (Bohra et al. 2006). The causes of such rainfall vagaries could be interaction of synoptic-scale weather systems with the meso-scale coastal land-surface features, along with poor prediction of magnitude, extent, and intensity of the rainfall by existing weather-forecast models (Bohra et al. 2006; Jenamani et al. 2006; Shyamala and Bhadram 2006; Lei et al. 2008; Chang et al. 2009). Additionally, Nayak and Ghosh (2013) found one of the crucial reasons for the occurrence of this extreme rainfall in western coast as the highspeed wind blowing from the Arabian Sea carrying excess moisture.

Lei et al. (2008) simulated the 26th July 2005 extreme rain event and its associated dynamical/ thermo-dynamical features using the Weather Research and Forecasting (WRF) model. They suggested this highly localized rain event was enhanced by the formation of a meso-scale vortex over Mumbai and due to an interaction between synoptic-scale weather systems and meso-scale coastal land-surface features. Further, Chang et al. (2009) tested three land surface models (LSMs), considering three nested domains (with 30, 10, and $3.3 \mathrm{~km}$ grid spacing) coupling it to the WRF, and investigated the ability of the WRF model to simulate this extreme event. Their results showed that the LSMs have a substantial impact on rainfall simulations.

The occurrence of the extreme rain event on 26th July 2005 subsequently elicited the inadequacy of having only two rainfall-recording weather observatories (at Colaba and Santacruz) set up by IMD in Mumbai. Thus, the Municipal Corporation of Greater Mumbai (MCGM) decided to install 26 rain gauging stations in the city in 2006 to capture the spatiotemporal pattern of rainfall in Mumbai (MCGM 2007; Lokanadham et al. 2009). Lokanadham et al. (2009) analysed the MCGM rain gauge network of 26 stations for the 3-5 July, 2006, event and concluded that Colaba and Santacruz, if individually considered to be representative of Mumbai rainfall, overestimate it by 11.5 and $16.6 \%$, respectively, thus highlighting the need for a dense rain gauge network in Mumbai for enhanced understanding of rain variation within the city.

Apart from research studies on this particular event, efforts have also been made to predict extreme rainfall over Mumbai using statistical techniques. Nayak and Ghosh (2013) attempted to develop an algorithm based on the machine-learning technique, support vector machine $(\mathrm{SVM})$, to 
predict extreme rainfall with a lead time of 6-48 hr in Mumbai, using meso-scale (20-200 km) and synoptic-scale (200-2000 km) weather patterns. Likewise, Nikam and Gupta (2013) developed a forecasting methodology using least-squares support vector machine (LS-SVM) and the probabilistic global search-Lausanne (PGSL) techniques for rainfall events $>25 \mathrm{~mm} / \mathrm{hr}$, which could not convincingly capture spatio-temporal variability.

Interestingly, along with such rainfall forecasting studies, efforts have also been made on design rainfall estimation for Mumbai. Sen et al. (2013) performed at-site design rainfall estimation for two gauging stations (Colaba and Santacruz) using 43 years (1969-2012) rainfall data in Mumbai for quantification of its spatio-temporal variability. The same dataset was used by Sherly et al. (2015a) to propose a framework for design rainfall estimation using multivariate semiparametric approach.

Several spatio-temporal studies have been conducted to comprehend rainfall extremes in other countries (Buytaert et al. 2006; Carrera-Hernández and Gaskin 2007) and, while several researchers have claimed the observance of high spatio-temporal variations in Mumbai rainfall (Lokanadham et al. 2009; Zope et al. 2015), these claims lack the backing of robust statistical analyses with finer scale rainfall data. Most of the above-mentioned studies performed for forecasting Mumbai rainfall, reveal the inadequacy of the sub-hourly rainfall data in bringing out any consequential understanding regarding its spatio-temporal variability. Hence, it is deemed appropriate that if the automatic rainfall monitoring initiative started by MCGM is carried forward uninterrupted for few more years, a significantly substantial dataset of high quality Mumbai rainfall will be generated. Application of sophisticated/advanced statistical analyses on such a robust and reliable dataset may lead to the capture of meaningful spatio-temporal patterns, which will further help in calibration and validation of weather models. Nevertheless, the present work is an original and well-thoughtout attempt to explore and analyse the sub-hourly rainfall dataset (created by the automated rain gauge stations installed by MCGM) for a potential understanding of spatio-temporal variations of extreme rain events in Mumbai. It is believed by the authors that this work, if complemented with the application of physics-centred WRF Models on the future advent of more robust databases, shall prove favourable for more accurate extreme event prediction. Thus, we can substantiate the belief that scrutinizing and analysing the occurrence of extreme rainfall events is imperative for both researchers and policymakers for the intentional development of mitigation strategies against urban disasters such as floods.

\section{Study area and rainfall data}

Mumbai city extends between $18.00^{\circ}-19.20^{\circ} \mathrm{N}$ and $72.00^{\circ}-73.00^{\circ} \mathrm{E}$ covering a total area of $437.79 \mathrm{~km}^{2}$ and holding an average population density of $27209 / \mathrm{km}^{2}$ (Government of Maharashtra 2006). The city consists of two revenue districts under the MCGM - Mumbai City district $\left(67.79 \mathrm{~km}^{2}\right)$ and Mumbai suburban district $\left(370 \mathrm{~km}^{2}\right)$ (Sherly et al. 2015b). It experiences a humid climate, being located on the southwest monsoon belt, with an average annual rainfall of $\sim 2500 \mathrm{~mm}$, of which $\sim 70 \%$ occurs in July and August (Hallegatte et al. 2010). The city is physico-geographically prone to various natural and human-induced hazards, including floods, cyclones, earthquakes, landslides, fires, and industrial and chemical accidents. It faces floods almost annually due to extreme rainfall events. Mumbai was originally a cluster of islands, and in due course of time, many areas were reclaimed to meet the demand of space. This has resulted in its inherent vulnerability to floods with the low-lying regions at or below mean sea level (Government of Maharashtra 2006). The largest flood occurred on 26 July 2005, when an unanticipated $944 \mathrm{~mm}$ of rainfall was measured in $24 \mathrm{hrs}$ along with a simultaneous high tide of $4.48 \mathrm{~m}$; claiming around 500 lives and incurring USD 2 billion in damages (Hallegatte et al. 2010). Accurate prediction of such extreme rainfall events thus commands utmost importance for preventive disaster planning and management. Prediction of floodcausing potential of an area can be best done by analysing the pattern of rainfall movement as it moves from one extreme gauge to another, measured sub-hourly (Sherly et al. 2015a). Also, the quality of rainfall estimation can be improved only by increasing the density of monitoring network (Buytaert et al. 2006). The 26th July, 2005 extreme rainfall event propelled the authorities to set up 26 rain gauge stations in June 2006, which was increased to 60 over a period of time for continuous and consistent rainfall measurement, with the intention of utilizing the built-up database for future research and analyses. However, just as any system takes time to establish, the 60 stations took more than 5 years for stability and continuity of rainfall monitoring.

It should be noted that, ideally, the selection of an optimal location for installing AWS should be made following different methodologies such as the ones discussed in Mishra and Coulibaly (2009, 2010), because choosing appropriate (optimal) sites for rain gauging is in itself a relevant research topic with huge potential. However, due to several bureaucratic conflicts, immense pressure from the public for quick solution-finding, and ground issues such as fear of vandalism of rain-gauge equipment 
by slum-dwellers, the MCGM chose to act fast and installed rain gauges at the 60 existing local firestation premises (which were reasoned out to be potentially safer and convenient). An ideal solution would have been to research exhaustively through different hydrometric network designs before setting up an optimal network of rain gauges in Mumbai city that can capture rainfall variability. Thus, fortunately or unfortunately, we were bound to use the data generated by the AWS set up by MCGM in the 60 local fire stations.

Sub-hourly (15-min interval) recorded rainfall data at 60 rain gauge stations, for the period of the southwest monsoon rainfall between June and September, for 2006 to 2014, was made available by MCGM. However, based on data consistency, continuity and reliability, the present study considered only 2013 and 2014 rainfall data recorded at 15-min temporal scale from 27 significant rain gauging stations in Mumbai; the remaining years data had an untreatable amount of missing values. The names, approximate coordinates and elevation values of the 27 rain gauging stations have been shown in figure 1 and table 1 . For the current study, the 10 most extreme rainfall days during 2013 and 2014 were considered for further analysis.

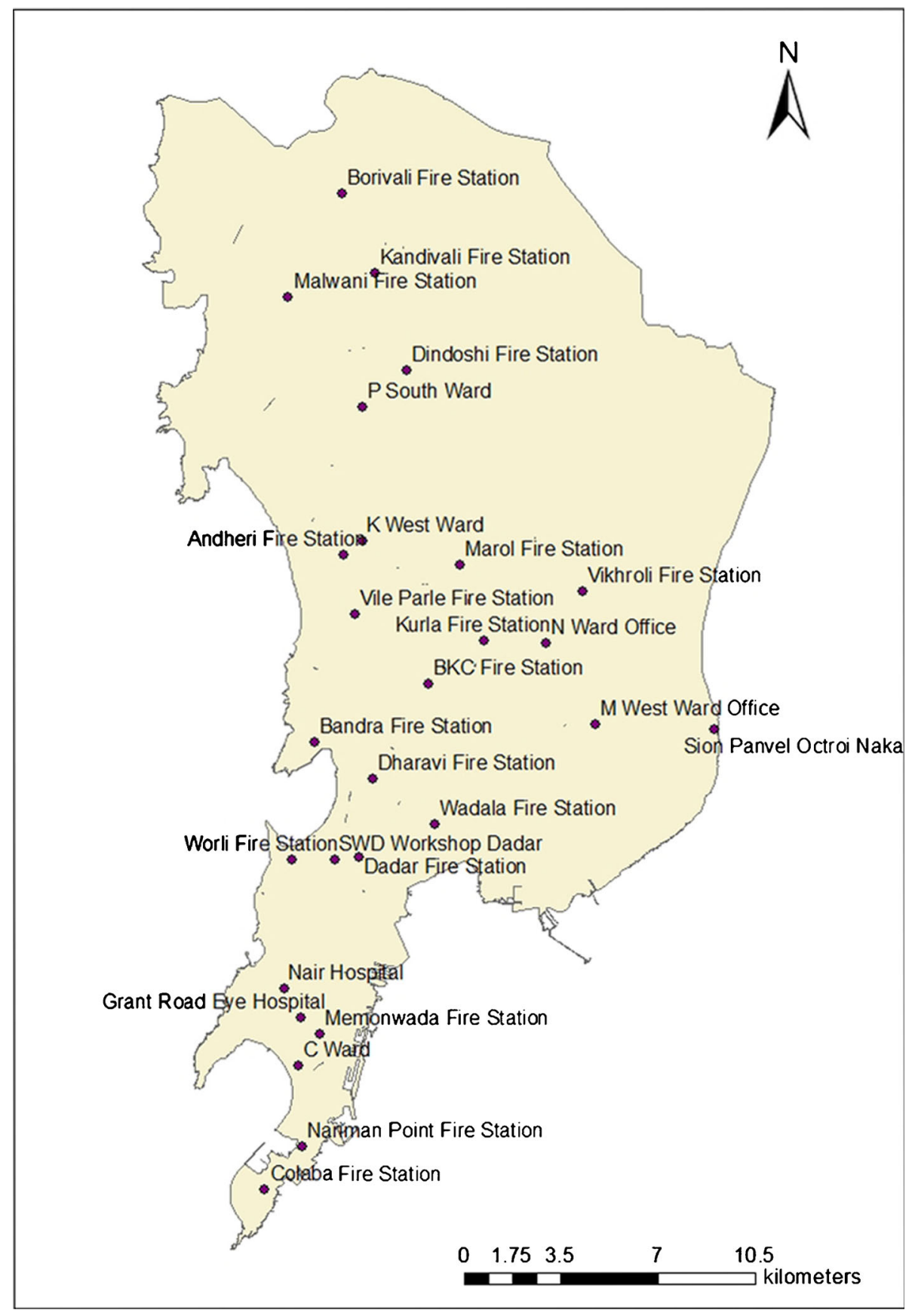

Figure 1. Location of 27 MCGM rain gauge stations in Mumbai used for the present study. 
Table 1. Details of 27 MCGM rain gauge stations in Mumbai used for the present study.

\begin{tabular}{|c|c|c|c|c|}
\hline Sl. no. & Station name & $\begin{array}{l}\text { Latitude } \\
\qquad(\mathrm{N})\end{array}$ & $\begin{array}{l}\text { Longitude } \\
\text { (E) }\end{array}$ & $\begin{array}{c}\text { Elevation } \\
(\mathrm{m})\end{array}$ \\
\hline 1 & Colaba Fire Station & $18^{\circ} 54^{\prime} 21^{\prime \prime}$ & $72^{\circ} 48^{\prime} 52^{\prime \prime}$ & 11 \\
\hline 2 & Nariman Point Fire Station & $18^{\circ} 55^{\prime} 12^{\prime \prime}$ & $72^{\circ} 49^{\prime} 37^{\prime \prime}$ & 0 \\
\hline 3 & C Ward Office & $18^{\circ} 56^{\prime} 46^{\prime \prime}$ & $72^{\circ} 49^{\prime} 32^{\prime \prime}$ & 15 \\
\hline 4 & Memonwada Fire Station & $18^{\circ} 57^{\prime} 23^{\prime \prime}$ & $72^{\circ} 49^{\prime} 58^{\prime \prime}$ & 9 \\
\hline 5 & Grant Road Eye Hospital & $18^{\circ} 57^{\prime} 43^{\prime \prime}$ & $72^{\circ} 49^{\prime} 35^{\prime \prime}$ & 14 \\
\hline 6 & Nair Hospital & $18^{\circ} 58^{\prime} 16^{\prime \prime}$ & $72^{\circ} 49^{\prime} 15^{\prime \prime}$ & 8 \\
\hline 7 & Worli Fire Station & $19^{\circ} 0^{\prime} 47^{\prime \prime}$ & $72^{\circ} 49^{\prime} 24^{\prime \prime}$ & 8 \\
\hline 8 & SWD Workshop Dadar & $19^{\circ} 0^{\prime} 47^{\prime \prime}$ & $72^{\circ} 50^{\prime} 14^{\prime \prime}$ & 9 \\
\hline 9 & Dadar Fire Station & $19^{\circ} 0^{\prime} 51^{\prime \prime}$ & $72^{\circ} 50^{\prime} 43^{\prime \prime}$ & 10 \\
\hline 10 & Wadala Fire Station & $19^{\circ} 1^{\prime} 29^{\prime \prime}$ & $72^{\circ} 52^{\prime} 12^{\prime \prime}$ & 3 \\
\hline 11 & Dharavi Fire Station & $19^{\circ} 2^{\prime} 21^{\prime \prime}$ & $72^{\circ} 50^{\prime} 59^{\prime \prime}$ & 6 \\
\hline 12 & Bandra Fire Station & $19^{\circ} 3^{\prime} 4^{\prime \prime}$ & $72^{\circ} 49^{\prime} 52^{\prime \prime}$ & 11 \\
\hline 13 & BKC Fire Station & $19^{\circ} 4^{\prime} 12^{\prime \prime}$ & $72^{\circ} 52^{\prime} 5^{\prime \prime}$ & 3 \\
\hline 14 & M West Ward Office & $19^{\circ} 3^{\prime} 25^{\prime \prime}$ & $72^{\circ} 55^{\prime} 19^{\prime \prime}$ & 9 \\
\hline 15 & Vile Parle Fire Station & $19^{\circ} 5^{\prime} 34^{\prime \prime}$ & $72^{\circ} 50^{\prime} 38^{\prime \prime}$ & 8 \\
\hline 16 & Kurla Fire Station & $19^{\circ} 5^{\prime} 3^{\prime \prime}$ & $72^{\circ} 53^{\prime} 9^{\prime \prime}$ & 12 \\
\hline 17 & N Ward Office & $19^{\circ} 5^{\prime} 0^{\prime \prime}$ & $72^{\circ} 54^{\prime} 23^{\prime \prime}$ & 14 \\
\hline 18 & Andheri Fire Station & $19^{\circ} 6^{\prime} 43^{\prime \prime}$ & $72^{\circ} 50^{\prime} 26^{\prime \prime}$ & 14 \\
\hline 19 & Sion Panvel Octroi Naka & $19^{\circ} 3^{\prime} 19^{\prime \prime}$ & $72^{\circ} 57^{\prime} 39^{\prime \prime}$ & 1 \\
\hline 20 & Marol Fire Station & $19^{\circ} 6^{\prime} 32^{\prime \prime}$ & $72^{\circ} 52^{\prime} 41^{\prime \prime}$ & 17 \\
\hline 21 & K West Ward & $19^{\circ} 7^{\prime} 1^{\prime \prime}$ & $72^{\circ} 50^{\prime} 47^{\prime \prime}$ & 22 \\
\hline 22 & Vikhroli Fire Station & $19^{\circ} 6^{\prime} 0^{\prime \prime}$ & $72^{\circ} 55^{\prime} 4^{\prime \prime}$ & 19 \\
\hline 23 & P South Ward & $19^{\circ} 9^{\prime} 37^{\prime \prime}$ & $72^{\circ} 50^{\prime} 47^{\prime \prime}$ & 13 \\
\hline 24 & Dindoshi Fire Station & $19^{\circ} 10^{\prime} 20^{\prime \prime}$ & $72^{\circ} 51^{\prime} 39^{\prime \prime}$ & 28 \\
\hline 25 & Malwani Fire Station & $19^{\circ} 11^{\prime} 46^{\prime \prime}$ & $72^{\circ} 49^{\prime} 20^{\prime \prime}$ & 5 \\
\hline 26 & Kandivali Fire Station & $19^{\circ} 12^{\prime} 13^{\prime \prime}$ & $72^{\circ} 51^{\prime} 2^{\prime \prime}$ & 17 \\
\hline 27 & Borivali Fire Station & $19^{\circ} 13^{\prime} 47^{\prime \prime}$ & $72^{\circ} 50^{\prime} 23^{\prime \prime}$ & 10 \\
\hline
\end{tabular}

\section{Methodology}

In this study, a comprehensive statistical approach aimed at investigating the spatio-temporal characteristics of extreme rainfall over Mumbai has been attempted. The spatio-temporal rainfall analysis was performed using the highest 10 extreme rainfall days' data of years 2013 and 2014. We have defined extreme days based on the spatially averaged rainfall across 27 AWSs. This methodology section has been divided into two sub-sections wherein we discuss the statistical techniques applied to study (1) spatial and (2) temporal characteristics of Mumbai rainfall extremes.

\subsection{Spatial characteristics of sub-hourly rainfall}

A preliminary analysis was performed to explore the extreme rainfall data in order to understand the spatial behaviour as rainfall progresses from south to north Mumbai. This included computing correlations between rainfall measured at the base station (Colaba fire station - the southern-most station) and each of the remaining 26 rain gauge stations (located in increasing Euclidean distance from 'Colaba fire station' towards the other farthest station 'Borivali' in north Mumbai), considering lead-times of $0-120$ min separated through a sub-hourly scale. An additional representation was designed to view a different angle of the correlation analysis. Using extreme rainfall data of 10 days, the nonparametric Kendall $\tau$ correlation coefficients were computed for all possible pairs of 27 stations, i.e., 351 correlation coefficients for years 2013 and 2014 data, because the nonparametric Kendall $\tau$ test overcomes the limitations associated with parametric correlation tests, like Pearson's correlation coefficient (Vittal et al. 2015). These coefficients were then plotted against the corresponding Euclidean distances between these stations.

Further, semivariogram analysis has been applied to the 10-day extreme rainfall dataset to characterize the spatial autocorrelation between rain gauging stations; its main highlight is a graph that plots the semivariance (i.e., the spatial dependence between rainfall at two gauging stations measured as a function of distance between them) on the y-axis corresponding to the distance between each pair of gauging stations on the $\mathrm{x}$-axis. The semivariogram determines the rate of change of rainfall along 
a spatial orientation (Davis and Sampson 1986). Semivariance is theoretically defined as the sum of the squared differences between pairs of stations separated by a certain distance divided by two times the number of stations in a distance class (Cressie 1993; Haan 2002; Buytaert et al. 2006; Carrera-Hernández and Gaskin 2007). Semivariance, also known as the semivariogram value, $\hat{\gamma}(h)$, is calculated based on classical (moments) estimator method, as per the following equation:

$$
\hat{\gamma}(h)=\frac{1}{2 N(h)} \sum_{i=1}^{N(h)}\left(Z_{i}-Z_{i+h}\right)^{2},
$$

where $N(h)$ denotes the set of pairs of stations $i$ and $i+h$ such that distance between $Z_{i}$ and $Z_{i+h}$ is $h$ and $N(h)$ is the number of pairs in the set. Theoretically, neighbouring gauging stations measure similar rainfall and have smaller semivariance; the semivariance is supposed to increase with increasing Euclidean distance between pairs of gauging stations. The semivariogram, in general, evens out after a particular distance forming a logarithmic curve, signifying the existence of spatial autocorrelation in the dataset till the sill and then non-correlation between the pairs of stations beyond the sill. Semivariogram also helps in understanding the movement of rainfall in more than one direction (Cressie 1993; St-Onge and Cavayas 1997); it reveals if the rainfall data is either isotropic (data varies in a similar way in all directions) or anisotropic (data varies differently in different directions). In the current study, four directions (omni-direction, north-south, east-west, southwest-northeast) have been investigated, and therefore four semivariograms were plotted for each of the 10 extreme days in 2013 and 2014.

In addition to the above graphical representations created for studying spatial autocorrelation of extreme rainfall data, Moran's I test (Moran 1950) has been applied for mathematical interpretation of the same. Moran's $I$ is a numerical measure of spatial autocorrelation computed to understand how related the rainfall is, based on the gauging stations they were measured at Moran's autocorrelation coefficient, denoted as ' $I$ ', is an extension of Pearson product-moment correlation coefficient to a univariate series. In spatio-statistical studies, it is logically expected that closer gauging stations are more likely to record similar rainfall than those far apart. It is usual to associate a weight to each pair $\left(x_{i}, x_{j}\right)$ of stations that quantifies this logic (Cliff and Ord 1981; Gittleman and Kot 1990). In its simplest form, these weights will take values 1 , for close neighbours, and 0 otherwise. We also set $w_{i i}=0$. These weights are sometimes referred as a neighbouring function. The mathematical expression of
Moran's autocorrelation coefficient $I$, is defined as the following:

$$
I=\frac{n}{S_{0}} \frac{\sum_{i=1}^{n} \sum_{j=1}^{n} w_{i j}\left(x_{i}-\bar{x}\right)\left(x_{j}-\bar{x}\right)}{\sum_{i=1}^{n}\left(x_{i}-\bar{x}\right)^{2}},
$$

where $w_{i j}$ is the weight between rainfall observations at stations $i$ and $j, \bar{x}$ is the sample mean of rainfall at all stations ( $x$ is the random variable, which is rainfall volume in this study) and $S_{0}$ is the sum of all $w_{i j}$. Here ' $n$ ' is fixed and always equal to 27 (same as the no. of AWSs). Also, $(i, j)$ here, is a pair of stations; for each $i$ th station, $j$ th station takes values from 1 to 27 . A binary distance matrix has been used to represent weights between gauging stations $\left(w_{i j}\right)$. Herein, we choose a distance of $1 \mathrm{~km}$ such that pairs of gauging stations within $1 \mathrm{~km}$ are considered connected and pairs with distance $>1 \mathrm{~km}$ are considered disconnected, and this binary weight matrix is then used to calculate Moran's I as seen in equation (2).

\subsection{Temporal characteristics of sub-hourly rainfall}

Mumbai receives $\sim 122$ days of rainfall throughout the monsoon; however, the recorded intensities are comparatively different. Rainfall intensity is higher during the middle of the monsoon and relatively lower near the beginning and end. Hence, it is crucial to have a thorough understanding of the temporal distribution of rainfall data and capture the pattern effectively; Gini index concept has thus been employed for the same. Traditionally, given the status of a powerful economic indicator, Gini index is used to measure the degree of inequality in the distribution of family income in a nation. It varies from 0 to 1 ; with 0 pointing towards perfect equality and 1 towards maximal inequality. However, recent researchers are exploring its possibilities in hydro-climatology amongst other fields (Ceriani and Verme 2012; Rajah et al. 2014). In the context of our analysis, the dimensionless Gini index provides a measure of how unevenly rainfall is distributed over a day and ranges from 0 (representing a uniform distribution of rainfall throughout the day) to 1 (representing the case where all the rainfall occurs in a single $15 \mathrm{~min}$ interval). Gini index is a robust and easily interpretable tool for measuring variability, as compared to the dispersion techniques that are sensitive to scale and probability distribution (Ceriani and Verme 2012; Rajah et al. 2014). To estimate the Gini index, daily rainfall data has been sorted in increasing order of depth and summed up cumulatively before their conversion to the percentage of total rainfall, leading to the formation of a Lorenz curve. The Gini index is calculated by doubling the area between the $45^{\circ}$ line (representing a 
uniform rainfall distribution) and the Lorenz curve, as shown in equation (3):

$$
G=\frac{1}{n}\left(n+1-2\left(\frac{\sum_{i=1}^{n}(n+1-i) y_{i}}{\sum_{i=1}^{n} y_{i}}\right)\right),
$$

where $n$ is the number of observations, $y_{i}$ represent the rainfall volume corresponding to any observation $i$. Further, the trend of Gini indices has been investigated following the procedure reported by Singh et al. (2015).

\section{Results and discussion}

In the current study, a comprehensive statistical analysis has been carried out over the 10 most extreme days using 2013-2014 rainfall sub-hourly data to identify and analyse the spatio-temporal characteristics of Mumbai extreme rainfall. However, we would like to mention that in our analysis, the southern-most AWS (i.e., Colaba station) was selected as the base station, since, ideally, rainfall over Mumbai progresses from southern Mumbai towards northern Mumbai during south-west monsoon. We have used 15-min interval data wherein one lag/lead indicates rainfall on 15 min prior/post and two lag/lead indicates rainfall on $30 \mathrm{~min}$ prior/post and so on and so forth. In figure 2, rainfall time series at Colaba has been considered at lag and remaining stations have been considered at lead from 0 to 120 min with an interval of 15 min. For example, correlations computed between rainfall measured at Colaba at, say $15.00 \mathrm{hrs}$ and rainfall measured at remaining stations at $15.15 \mathrm{hrs}$ have been displayed.

A correlogram structure is derived between the rainfall recorded at the base station and rainfall recorded at each of the remaining 26 stations, to study the spatial variation in extreme days' rainfall. Herein, the coefficients are arranged based on Euclidean areal distance of each gauging station from the base station, for each extreme day, in order to observe the change in correlation with increase in the distance between the base and remaining stations. Each correlogram between the base and other 26 gauging stations has been constructed from 0 to $120 \mathrm{~min}$ lead-time with $15 \mathrm{~min}$ interval. Rainfall time series at Colaba has been considered at lag and remaining stations have been considered at lead. For example, correlations computed between rainfall measured at Colaba at, say $15.00 \mathrm{hrs}$ and rainfall measured at remaining stations at $15.15 \mathrm{hrs}$ have been displayed.

Figure 2 depicts a set of correlograms each for the 3rd, 6th, 7th and 9th of the 10 extreme days from years 2013 and 2014. Herein, rows and columns represent the spatial and temporal scales, respectively, blue and orange colours represent significant correlation from (0 to 1$)$ and ( -1 to 0 ), respectively, and the cross sign represents insignificant correlation. In case of the zero minute leadtime, a pattern of significant correlation is not observable, quite unexpectedly, when we consider the closest to farthest gauging station from the base station (from 'Colaba fire station' to 'Borivali') based on Euclidean distance between gauging stations, except on the 3rd extreme day in 2013. Similarly, in the case of 15-min, 30-min and other lead-times, two 'opposed-to-theory' features were observed: one was that stations closer to base station showed insignificant correlation while few gauging stations that are relatively farther from the base station showed a significant correlation, and another was a negative correlation between the gauging stations. Such observance of a non-patterned correlogram structure leads us to state that it seems highly unlikely that sophisticated statistical interpolation techniques such as kriging, cokriging, conditional simulation and inverse distance weighting, may be of substantial use for prediction of spatio-temporal variability of Mumbai rainfall.

Further, in figure 3, the correlation values between rainfall at every possible pair of the 27 gauging stations have been plotted against the Euclidean distance between corresponding stations. That is to say, a set of $(n(n-1) / 2)$ correlation coefficients (in our case, $n$ is 27) translating to 351 correlation coefficients have been computed for each of the 10 extreme rainfall days in the year 2013 and 2014. Black circles represent correlations between pairs of stations for 2013 rainfall and orange circles for 2014 rainfall observations. The band formed by two blue lines represents $5 \%$ level of significance. The rainfall correlation coefficients are considered statistically significant if they lie outside the blue line band. The correlation coefficients against the distance between gauging stations as observed in 10 extreme days in 2013 reveal that closer stations show lower correlation coefficient values (figure 3a, $\mathrm{f}, \mathrm{g}, \mathrm{i})$ and distant stations show higher correlation coefficient values (figure $3 \mathrm{c}, \mathrm{d}, \mathrm{e}, \mathrm{h}$ ). A similar pattern was also observed in 2014 as seen in figure $3(\mathrm{~b}, \mathrm{e}, \mathrm{g}, \mathrm{h})$. No pattern of significant correlation was observed in pairs of gauges located farther than $5 \mathrm{~km}$. In most cases, correlation and distance vary inversely except on 4 th, 5 th and 10 th extreme days (figure 3d, e, h) in 2013. Figure 3(e) shows the 5 th extreme day with $90 \%$ of coefficients to be significant in 2013. Another point to note is that almost $50 \%$ pairs of gauging stations lie within the blue line band of insignificant correlation. As expected, most of the correlation coefficients are positive, which translates to it being hard to capture any trend or pattern of significant correlation between pairs of rain gauging stations. To conclude this discussion on correlation behaviour 


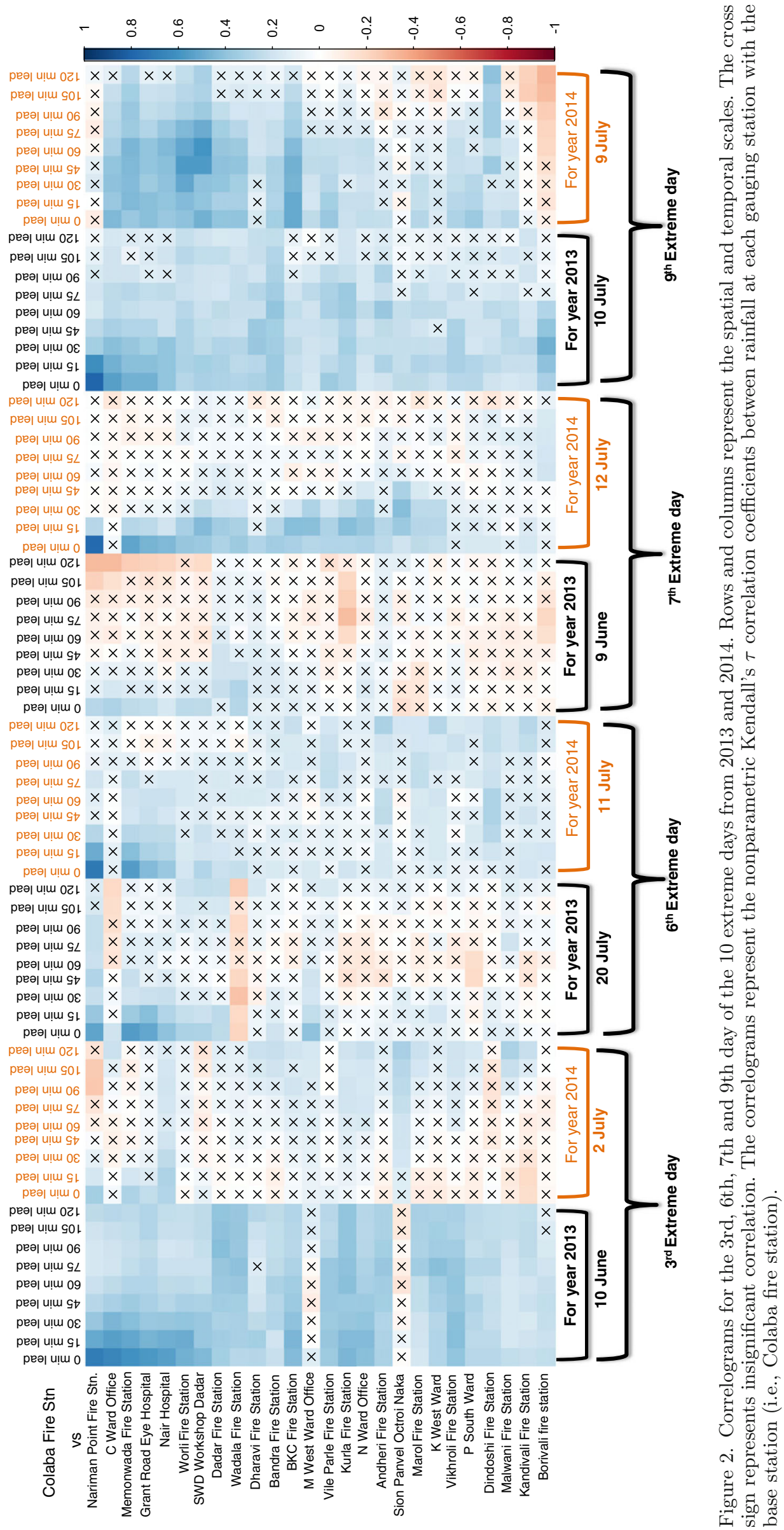



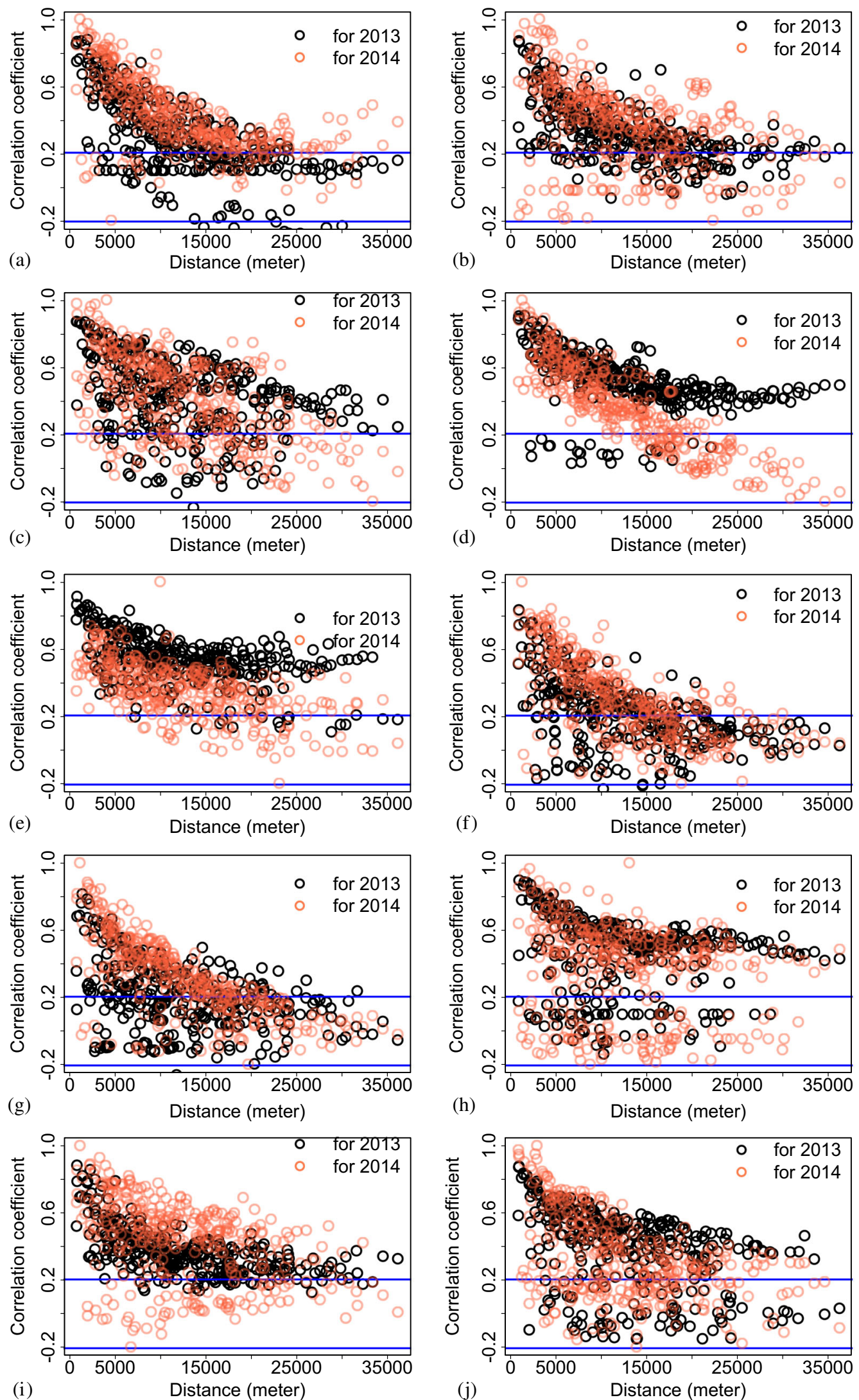

Figure 3. Nonparametric Kendall's $\tau$ correlation coefficients between rainfall at every possible pair of the 27 rain gauging stations against the Euclidean distance between corresponding stations, for each of the 10 extreme days. In short, 351 correlation coefficients have been plotted against their corresponding distances. Black circles represent correlations for the 2013 rainfall and orange circles for the 2014 rainfall. The blue line band represents $5 \%$ level of significance. Almost $50 \%$ pairs of stations fall within the blue line band, thus showing insignificant correlation. 
between the rainfall recorded at rain gauges, the correlation values have turned out to be opposite of what the first law of geography says, "Everything is related to everything else, but near things are more related than distant things." (Tobler 1970). And this law is paradoxically the foundation of the fundamental concepts of spatial dependence and spatial autocorrelation.

Additionally in figure 4, semivariograms were meticulously constructed for each of the 10 extreme rainfall days in years 2013 and 2014, considering both isotrophic (omni-directional depicted in black) and anisotrophic (north-south in blue, east-west in red and southwest-northeast in green) semivariograms for in-depth understanding of spatial autocorrelation/variability in rainfall (i.e., its movement in more than one direction), which usually facilitates spatial prediction. Figure 4 clearly shows that the closer and farther gauging stations produce higher and lower semivariance, respectively, regardless of direction, as opposed to the theoretical definition of a semivariogram. Theoretically,
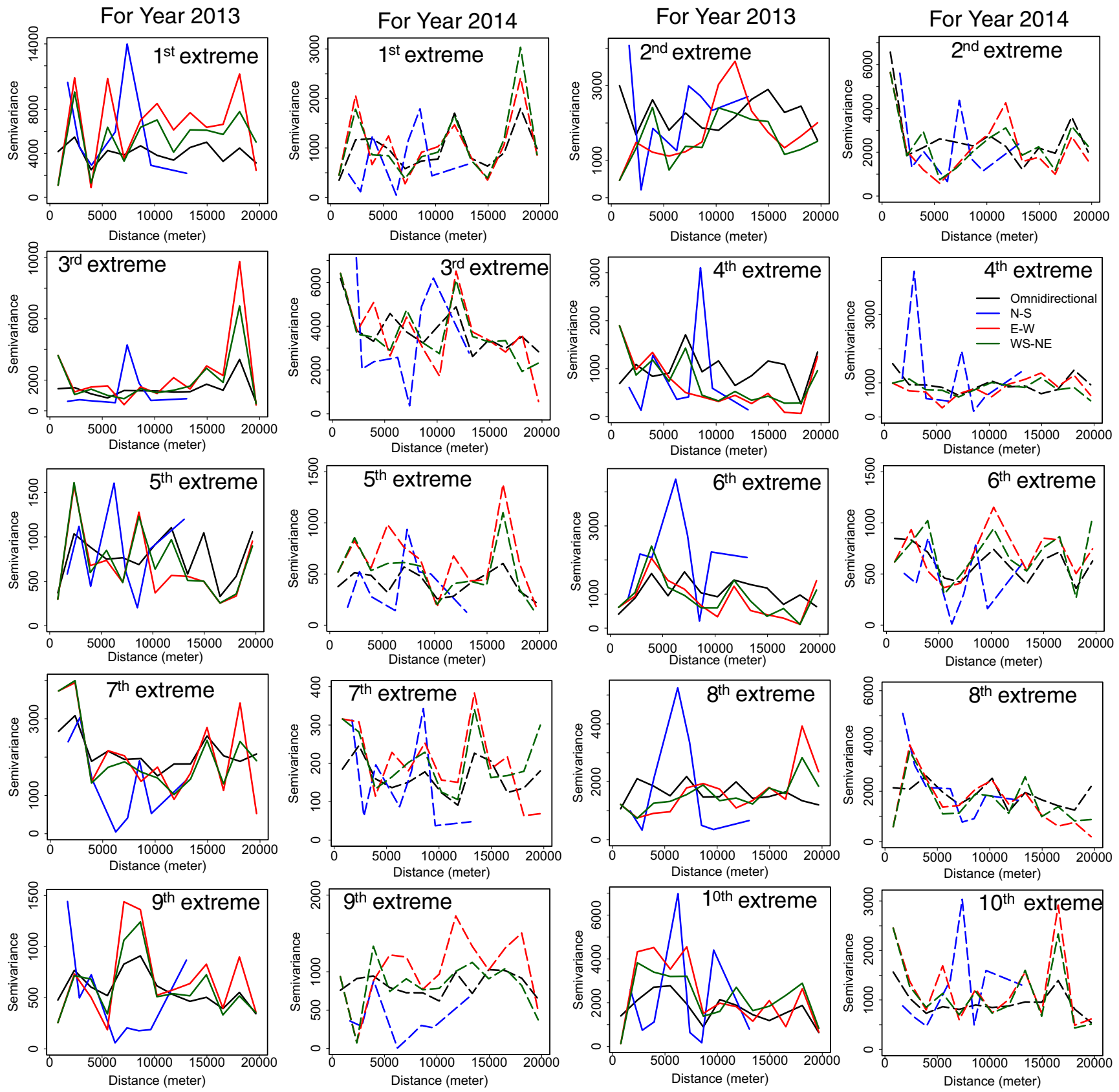

Figure 4. Semivariogram plot for each of the 10 extreme rainfall days in 2013 and 2014, considering both isotropic (omnidirectional depicted in black) and anisotropic (north-south in blue, east-west in red and southwest-northeast in green). Solid lines are depicted for 2013 and dots for 2014. The x-axis shows the distance between gauge stations in meters and y-axis shows the corresponding semivariance. 
semivariogram displays a logarithmic curve rising monotonically as a function of distance, showing high spatial autocorrelation till the sill (semivariogram upper bound) and then no correlation beyond the range (the distance at which the semivariogram reaches the sill) (Carrera-Hernández and Gaskin 2007). The random zigzag pattern observed in all sub-plots of the semivariograms confirms high spatial autocorrelation in the extreme rainfall of 2013 and 2014.

Figure 5(a) shows the temporal distribution of sub-hourly rainfall data. Herein, the 2013 and 2014 rainfall data has been displayed as four different duration spells to study diurnal rainfall variability: 0-6 hrs (night, black curve), 6-12 hrs (morning, blue curve), 12-18 hrs (afternoon, red curve), 180 hrs (evening, green curve). Rainfall depth during morning and afternoon is very high for the first two monsoon months, i.e., June and July (these months contributed towards $80 \%$ of total rainfall that occurred in 2013, as seen in the pie chart in figure 5(b), whereas it showed similar rainfall volume for all four duration spells in remaining monsoon months of August and September in 2013 (figure 5a). Figure 5(c) displays the rainfall distribution for all duration spells in 2013, where it is seen that rainfall density in afternoon hours (red curve) shows the highest variation as compared to other duration spells. However, the scenario is different for 2014 rainfall (figure 5d), wherein most of the rainfall occurred in the month of July, which contributed towards $63 \%$ of total rainfall occurred in 2014 (as seen in the pie chart in figure 5e). Figure 5(f) displays the rainfall distribution for all duration spells in 2014, wherein the morning hours' (blue curve) rainfall density shows the highest variation as compared to other duration spells. Further, figure 5(c) and (f) show that night rainfall (18-6 hrs slot) is lesser compared to day rainfall (6$18 \mathrm{hrs}$ slot) for both 2013 and 2014, respectively. A possible reason could be the extra heat provided by the Urban Heat Island (UHI) leading to a greater upward motion that has the potential to induce additional shower and thunderstorm activity. Also, during daytime, the UHI creates a local low-pressure area, where relatively moist air from its rural surroundings converges, possibly leading to more favourable conditions for cloud formation (Heerwaarden and de Arellano 2008). However, a comprehensive hypothesis-driven physics-based modelling should be performed to understand the reason behind higher daytime rainfall over Mumbai.

This arbitrary variation in temporal rainfall distribution shows that it does not seem to be following any 'capture-able' pattern. The same temporal change is being reflected in the gauge-wise Gini index plots too, as shown in figure 6. It shows the daily Gini index developed using the 20132014 rainfall dataset for each of the 27 gauging stations in Mumbai; black and orange colours represent the daily Gini indices for 2013 and 2014 rainfall, respectively. A visibly vast majority of the Gini indices were $>0.8$ throughout the monsoon in all gauging stations. This change in temporal
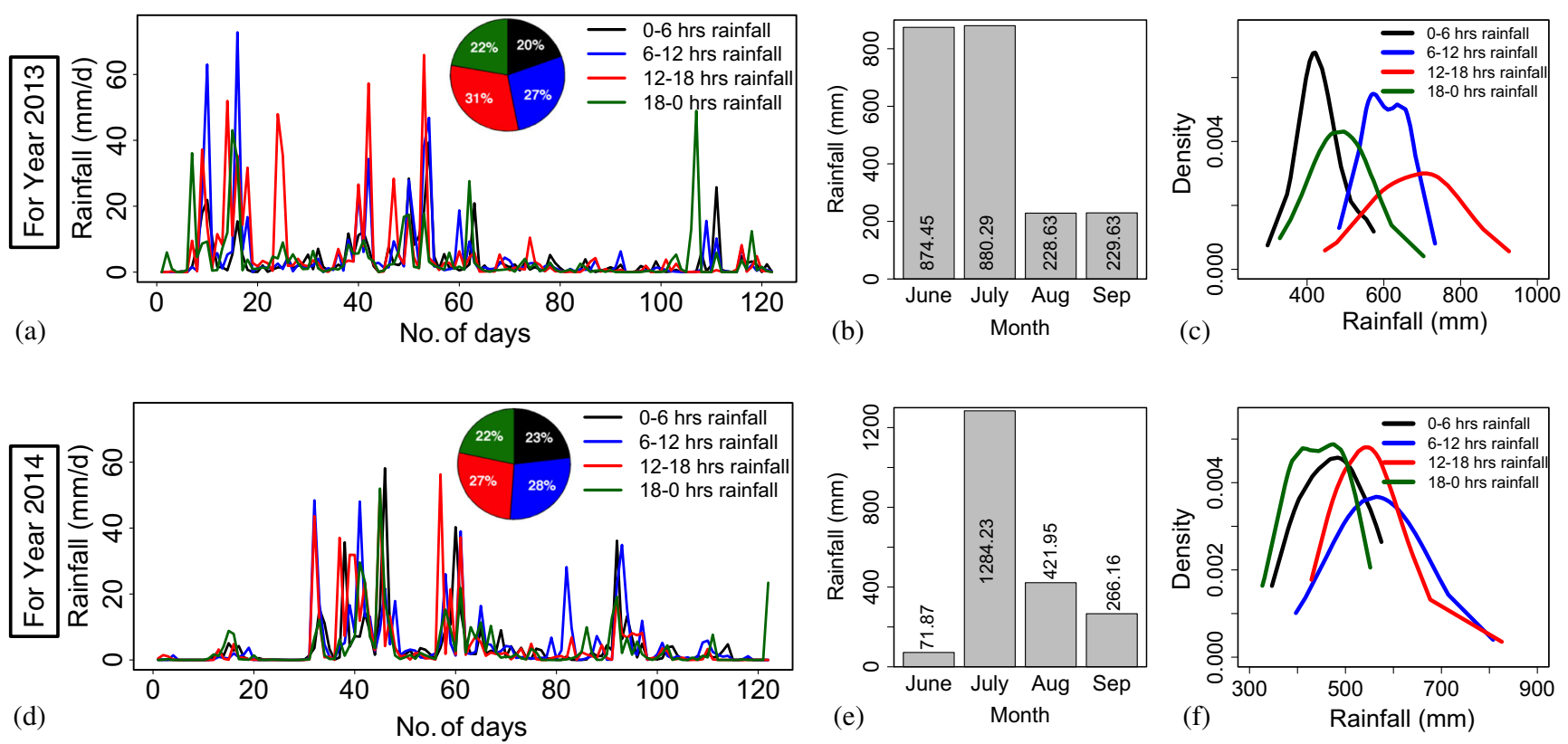

Figure 5. a(d) show the diurnal distribution of rainfall in 2013 (2014). The 2013 and 2014 rainfall data have been displayed as four different duration spells to study diurnal rainfall variability: 0-6 hrs (night, black curve), 6-12 hrs (morning, blue curve), 12-18 hrs (afternoon, red curve), 18-24 hrs (evening, green curve). Figures b(e) depict rainfall distribution in each monsoon month for 2013 (2014). Figures c(f) display the probability density function of diurnal rainfall for 2013 (2014). 

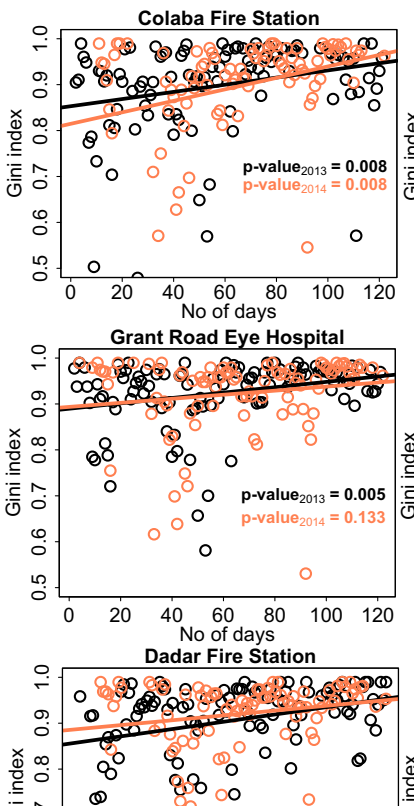

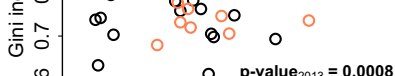

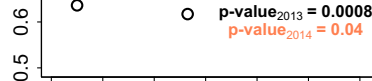

$\begin{array}{llllll}60 & 80 & 80 & 100 & 120\end{array}$

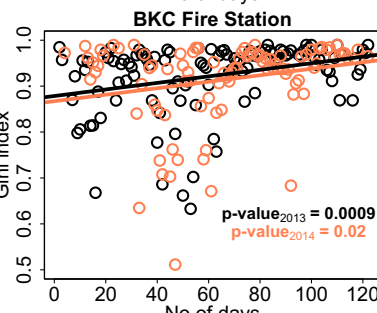
$\mathrm{N}$ Ward Office
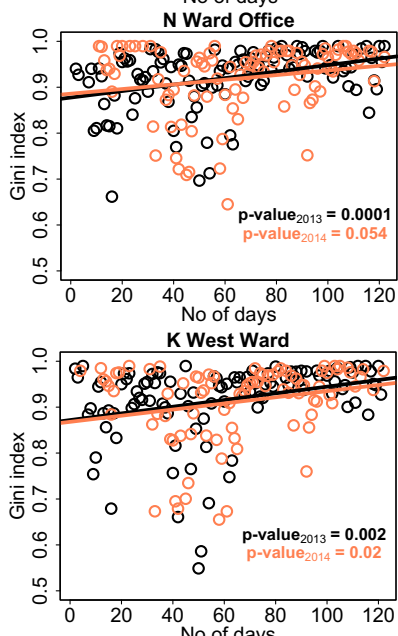
Malwani Fire Station

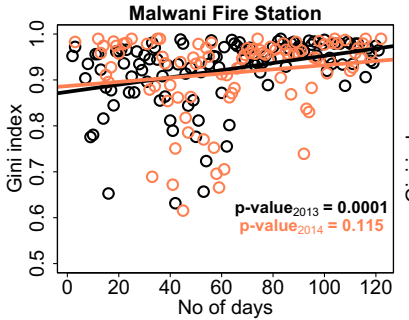

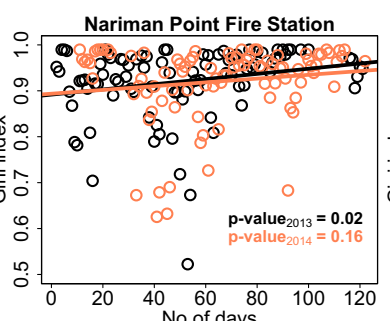
Nair Hospital

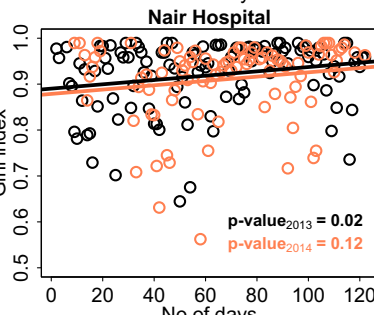

Wadala Fire Station

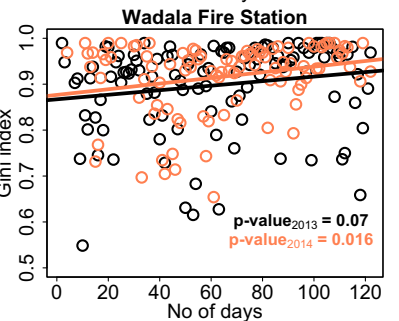

$M$ West Ward Office

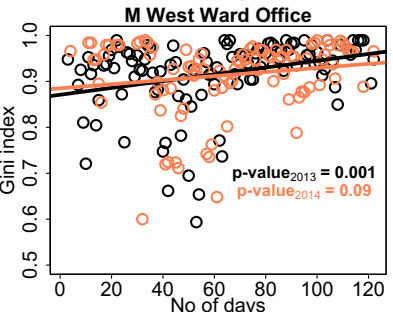

Andheri Fire Station

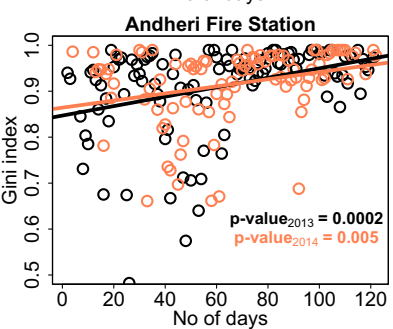

Vikhroli Fire Station
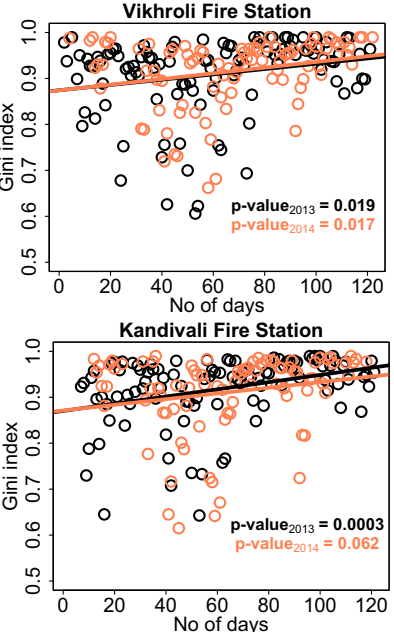
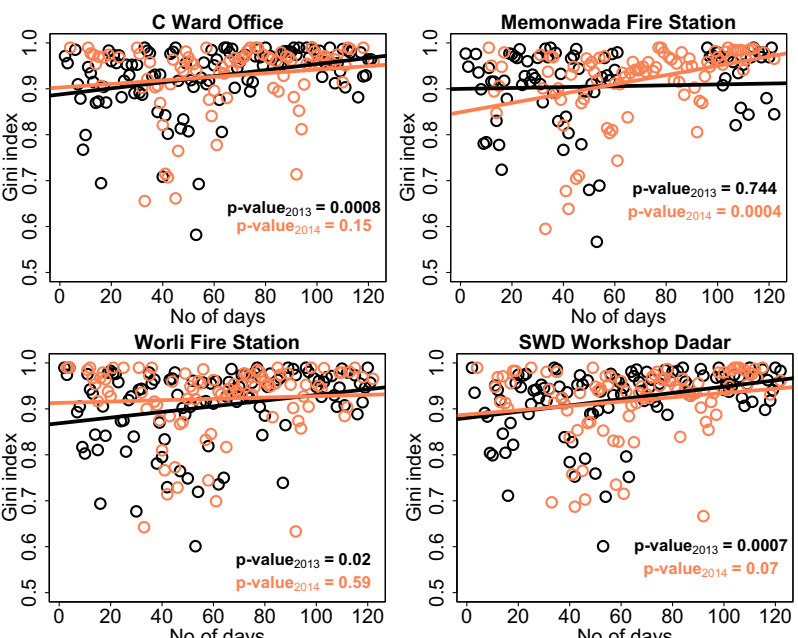

Dharavi Fire Station

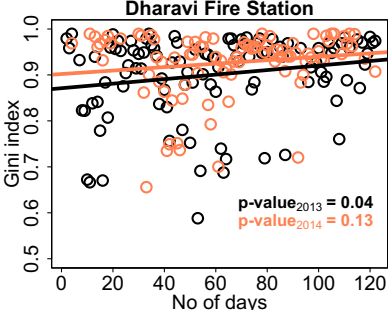

Vile Parle Fire Station

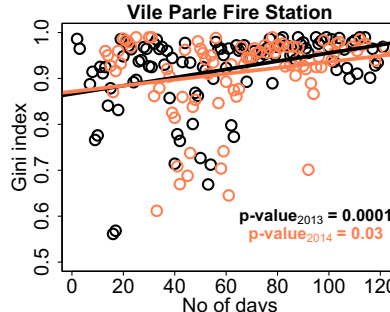

Sion Panvel Octroi Naka
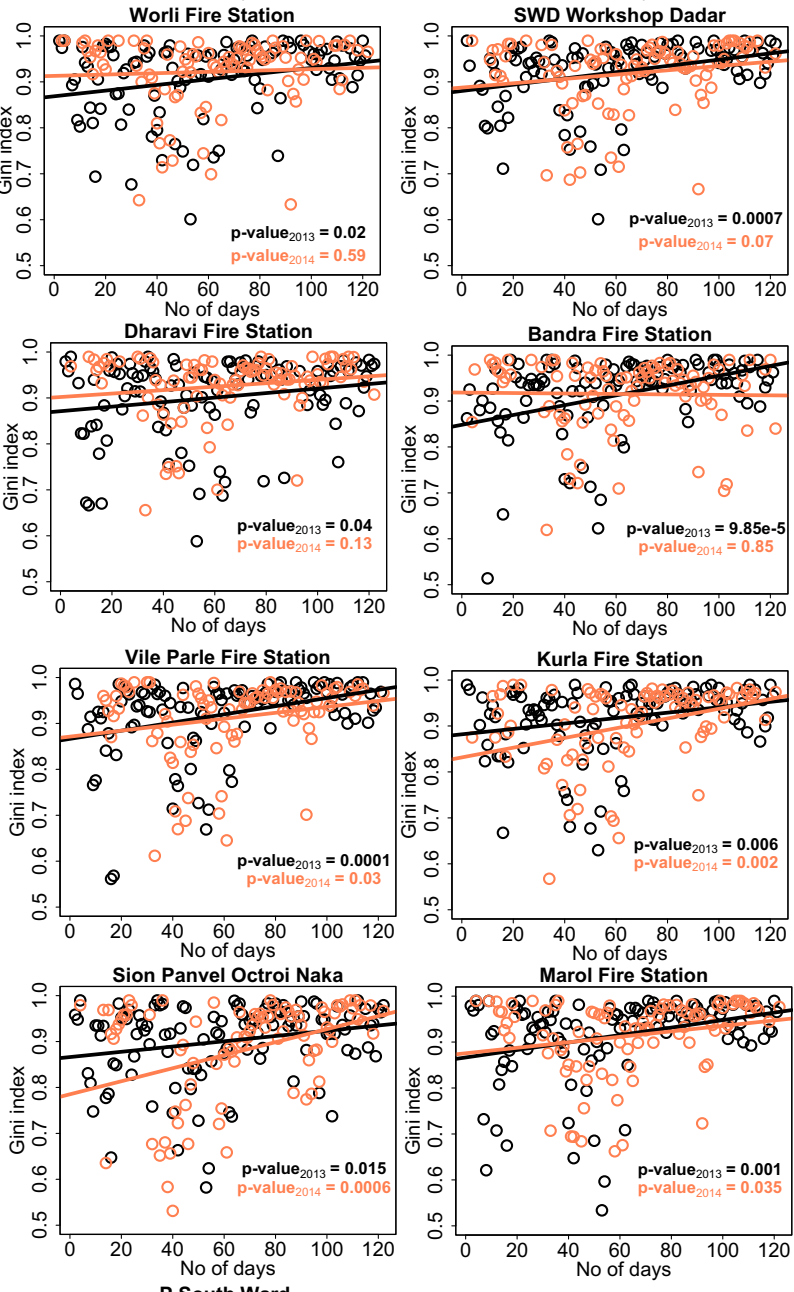

Bandra Fire Station
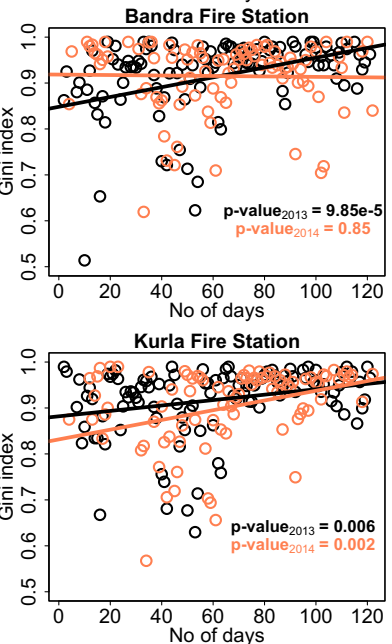

Marol Fire Station
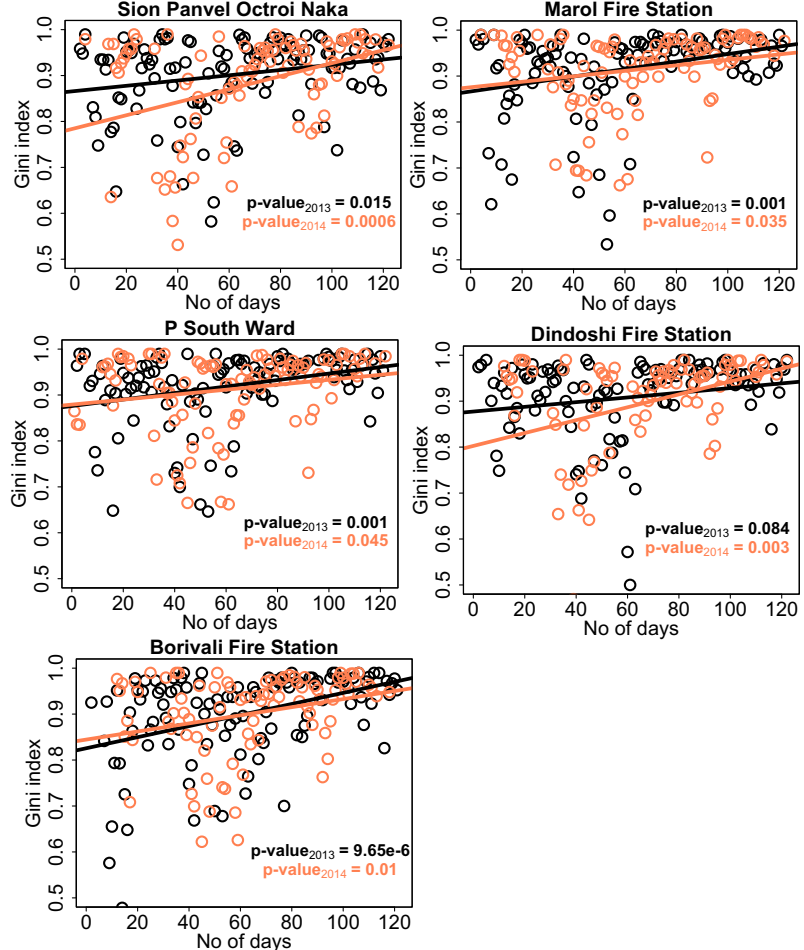

Figure 6. Daily Gini indices of sub-hourly rainfall for the 27 rain gauging stations in Mumbai. Black and orange colours represent the daily Gini indices for 2013 and 2014 rainfall, respectively. Solid black and orange lines show the trend in Gini indices for 2013 and 2014, respectively. 
Table 2. Results from spatial autocorrelation considering that the gauging stations lying within $1 \mathrm{~km}$ only are connected or have considerable similarities in rainfall.

\begin{tabular}{lccccc}
\hline Sl. no. & Observed I & Expected I & Std. dev. & $P$-value & Result \\
\hline For year 2013 & & & & & \\
1st extreme & 0.427 & -0.038 & 0.552 & 0.398 & No \\
2nd extreme & 0.029 & -0.038 & 0.566 & 0.904 & No \\
3rd extreme & 0.152 & -0.038 & 0.533 & 0.72 & No \\
4th extreme & 0.327 & -0.038 & 0.539 & 0.497 & No \\
5th extreme & 0.548 & -0.038 & 0.557 & 0.293 & No \\
6th extreme & $\mathbf{1 . 1 0 7}$ & $\mathbf{- 0 . 0 3 8}$ & $\mathbf{0 . 5 6 0}$ & $\mathbf{0 . 0 4 0}$ & Yes \\
7th extreme & -0.207 & -0.038 & 0.565 & 0.764 & No \\
8th extreme & -0.979 & -0.038 & 0.564 & 0.095 & No \\
9th extreme & $\mathbf{1 . 5 1}$ & $\mathbf{- 0 . 0 3 8}$ & $\mathbf{0 . 5 6 3}$ & $\mathbf{0 . 0 0 5}$ & Yes \\
10th extreme & 0.548 & -0.038 & 0.518 & 0.258 & No \\
For year 2014 & & & & & \\
1st extreme & 0.291 & -0.038 & 0.554 & 0.551 & No \\
2nd extreme & -0.543 & -0.038 & 0.552 & 0.361 & No \\
3rd extreme & 0.459 & -0.038 & 0.565 & 0.379 & No \\
4th extreme & $\mathbf{1 . 7 9}$ & $\mathbf{- 0 . 0 3 8}$ & $\mathbf{0 . 5 6 3}$ & $\mathbf{0 . 0 0 1}$ & Yes \\
5th extreme & $\mathbf{1 . 6 4}$ & $\mathbf{- 0 . 0 3 8}$ & $\mathbf{0 . 5 5 4}$ & $\mathbf{0 . 0 0 2}$ & Yes \\
6th extreme & 0.599 & $\mathbf{- 0 . 0 3 8}$ & 0.558 & 0.253 & No \\
7th extreme & 0.707 & $\mathbf{- 0 . 0 3 8}$ & 0.555 & 0.179 & No \\
8th extreme & 0.522 & $\mathbf{- 0 . 0 3 8}$ & 0.565 & 0.321 & No \\
9th extreme & 1.01 & $\mathbf{- 0 . 0 3 8}$ & 0.558 & 0.059 & No \\
10th extreme & $\mathbf{1 . 1}$ & $\mathbf{- 0 . 0 3 8}$ & $\mathbf{0 . 5 6 7}$ & $\mathbf{0 . 0 4 5}$ & Yes \\
\hline 'No' stands for no significant autocorrelation or spatial randomness of 27 & gauging \\
station location and 'Yes' stands for & significant autocorrelation. & &
\end{tabular}

Gini index pattern, pointing towards 1.0 in most cases, sufficiently concludes the non-uniformity in the rainfall through the day. A linear trend has been fitted over the indices and observed to be significantly increasing $(P$-value $<0.05)$ in $25 / 27$ gauging stations in 2013. This trend indicates the increasing non-uniformity in the daily rainfall as monsoon progresses from June to September. A similar conclusion may be drawn from the rainfall data in 2014.

Further, spatial autocorrelation values were computed between rainfall measured at different gauging stations using the Moran's I test as seen in table 2. Spatial autocorrelation is complex as compared to unidirectional autocorrelation in times series data as it is multidirectional as well as multidimensional. A positive Moran's I suggests similarity (either high or low) and a negative value indicates dissimilarity (Anselin and Rey 2010). Table 2 depicts that insignificant spatial autocorrelation has been observed for $8 / 10$ and $7 / 10$ extreme days for the years 2013 and 2014, respectively. Also, for few extreme days, Moran's I values were found to be negative indicating dissimilarity in rainfall recorded at AWS.

Mumbai experiences heavy orographic rainfall due to its strategic location on the windward side of Western Ghats. In addition, the surface roughness caused due to clusters of tall buildings and hillocks plays a major role in increasing surface drag and wake turbulence (turbulent wake layer generates above the urban canopy layer), and decreases wind speed (Roth 2000; Collier 2006). Due to such heterogeneous surface roughness condition and generation of local heat-plumes by UHIs, atmospheric boundary layer (ABL) increases over the warmer patches (high Bowen ratio) and decreases over the colder patches (low Bowen ratio). The greater ABL heights over the warmer patches lead to lower absolute temperatures over the centre of the warmer patches, and subsequently, cloud formation becomes favourable over the warmer patches of a heterogeneous landscape (Heerwaarden and de Arellano 2008). These local processes might be responsible for imparting spatial heterogeneity in rainfall distribution over Mumbai.

\section{Conclusions}

The current study is a maiden attempt to analyse the spatio-temporal characteristics of extreme rainfall over Mumbai. Post the 2005 flash floods, in a serious attempt to accurately predict any forthcoming extreme events in Mumbai, MCGM, took the onus of installing 26 AWS in June 2006, which 
gradually increased to 60 . A thorough analysis of available rainfall data for 2006-2014 from these stations subsequently revealed that the set of 2013-2014 sub-hourly data from 27 AWS was discovered to be useful for further analyses as it was comparatively consistent, continuous and complete. Rigorous statistical analyses were performed to understand the spatio-temporal pattern of Mumbai extreme rainfall. The prime observation was, as also supported by poor inter-station rainfall correlations, a great degree of variability that did not disclose any rational pattern in rainfall extremes. In addition to this, semivariogram plots showed a strikingly opposite scenario of closer stations showing higher semivariance and vice-versa for distant stations, irrespective of the direction of rain movement, thus indicating pattern-less spatial variability in rainfall extremes. Moran's I test also supports this result, as shown by the insignificant spatial autocorrelation among the extreme rainfall recorded in 27 gauging stations over Mumbai. Most of the monsoon days observed Gini indices, a statistical measure of temporal non-uniformity, $>0.8$, which sufficiently implies a temporal nonuniformity in rainfall over a day (i.e. 24-hr interval). Surprisingly, the indices also showed an increasing trend as monsoon progresses (i.e., June to September), which implies a lower temporal nonuniformity in rainfall over a day during the beginning of monsoon, but higher towards the end of monsoon. One more interesting observation was the night rainfall (18-6-hr slot) showing to be relatively lesser in comparison to daytime rainfall (6-18-hr slot). This unusual pattern of spatiotemporal behaviour of extreme rainfall over Mumbai may be associated with multiple physical factors (such as orographic effect, presence of a northwardmoving meso-scale offshore vortex over the northeast Arabian Sea, north-westward movement of low pressure systems from Bay of Bengal along the monsoon trough and wake turbulence caused by clusters of tall buildings and hillocks).

Further, we think the availability of a comparatively larger and robust rainfall dataset would have been more fruitful for an insight into the 'irrationality' component observed in the spatio-temporal behaviour. We foresee that if the automatic rainfall monitoring initiative started by MCGM is carried forward uninterrupted for few more years in sub-hourly format, a significantly robust and high-quality rainfall dataset of Mumbai will be generated. Application of advanced statistical analyses on such reliable dataset shall lead to the capture of rational spatio-temporal patterns, which will further help in calibration and validation of weather models. Despite this, for the nonce, we believe the spatio-temporal analysis of 2-yr sub-hourly Mumbai rainfall data is a beneficial attempt, particularly to realize the futility of independently applying advanced statistical techniques for rainfall forecasting, and thus calls for simultaneous inclusion of physics-centred models such as different meso-scale numerical weather prediction systems, particularly Weather Research and Forecasting (WRF) Model.

\section{Acknowledgements}

We gratefully acknowledge the Ministry of Earth Sciences, Govt. of India (Projects Ref. No. MoES/ PAMC/H\&C/36/2013-PC-572II and MoES/PAMC/ $\mathrm{H} \& \mathrm{C} / 35 / 2013-\mathrm{PC}-\mathrm{II})$ for the financial funding that led to successful completion of this research work. We also thank the Municipal Corporation of Greater Mumbai for providing the sub-hourly rainfall data. We sincerely thank the anonymous Reviewers and the associate editor for providing insightful suggestions, which improved the manuscript substantially.

\section{References}

Anselin L and Rey S J 2010 Perspectives on spatial data analysis; Springer, Berlin, 20p.

Bohra A K, Basu S, Rajagopal E N, Iyengar G R, Gupta M D, Ashrit R and Athiyaman B 2006 Heavy rainfall episode over Mumbai on 26 July 2005: Assessment of NWP guidance; Curr. Sci. 90(9) 1188-1194.

Buytaert W, Celleri R, Willems P, De Bievre B and Wyseure G 2006 Spatial and temporal rainfall variability in mountainous areas: A case study from the south Ecuadorian Andes; J. Hydrol. 329(3) 413-421.

Carrera-Hernández J J and Gaskin S J 2007 Spatio-temporal analysis of daily precipitation and temperature in the Basin of Mexico; J. Hydrol. 336(3) 231-249.

Ceriani L and Verme P 2012 The origins of the Gini index: Extracts from Variabilità e Mutabilità (1912) by Corrado Gini; J. Econ. Inequal. 10(3) 421-443.

Chang H I, Kumar A, Niyogi D, Mohanty U C, Chen F and Dudhia J 2009 The role of land surface processes on the mesoscale simulation of the July 26, 2005 heavy rain event over Mumbai, India; Global Planet. Change 67(1) 87-103.

Cliff A D and Ord J K 1981 Spatial processes: Models 86 applications; London: Pion, 266p.

Collier C G 2006 The impact of urban areas on weather; Quart. J. Roy. Meteorol. Soc. 132 1-25.

Cressie N 1993 Statistics for spatial data: Wiley series in probability and statistics; Wiley-Interscience, New York, Vol. 15, 16p.

Davis J C and Sampson R J 1986 Statistics and data analysis in geology; Wiley, New York, 646p.

Gittleman J L and Kot M 1990 Adaptation: Statistics and a null model for estimating phylogenetic effects; Syst. Biol. 39(3) 227-241.

Government of Maharashtra 2006 Fact Finding Committee on Mumbai Floods; Chitale Committee Report; Government of Maharashtra, India.

Hallegatte S et al. 2010 Flood risks, climate change impacts and adaptation benefits in Mumbai: An initial assessment of socio-economic consequences of present and climate 
change induced flood risks and of possible adaptation options; Environment Working Papers, No. 27. Technical Report. OECD Publishing.

Haan C T 2002 Statistical methods in hydrology; Iowa State Press, Iowa, 496p.

Hallegatte S, Green C, Nicholls R J and Corfee-Morlot J 2013 Future flood losses in major coastal cities; Nat. Clim. Change 3(9) 802-806.

Heerwaarden C C V and de Arellano J V G 2008 Relative humidity as an indicator for cloud formation over heterogeneous land surfaces; J. Atmos. Sci. 65(10) 32633277.

Jenamani R K, Bhan S C and Kalsi S R 2006 Observational/forecasting aspects of the meteorological event that caused a record highest rainfall in Mumbai; Curr. Sci. 90(10) 1344-1362.

Kumar A, Dudhia J, Rotunno R, Niyogi D and Mohanty U C 2008 Analysis of the 26 July 2005 heavy rain event over Mumbai, India using the Weather Research and Forecasting (WRF) model; Quart. J. Roy. Meteorol. Soc. 134(636) 1897-1910.

Lei M, Niyogi D, Kishtawal C, Pielke Sr R A, BeltránPrzekurat A, Nobis T E and Vaidya S S 2008 Effect of explicit urban land surface representation on the simulation of the 26 July 2005 heavy rain event over Mumbai, India; Atmos. Chem. Phys. 8(20) 5975-5995.

Lokanadham B, Gupta K and Nikam V 2009 Characterization of spatial and temporal distribution of monsoon rainfall over Mumbai; J. Hydraul. Eng. 15(2) 69-80.

MCGM 2007 Greater Mumbai Disaster Management Action Plan, Volume 1.

Mishra K and Coulibaly P 2009 Developments in hydrometric network design: A review; Rev. Geophys. 47 1-24.

Mishra K and Coulibaly P 2010 Hydrometric network evaluation for Canadian watersheds; J. Hydrol. 380 420-437.

Moran P A 1950 Notes on continuous stochastic phenomena; Biometrika 37(1/2) 17-23.

Nayak M A and Ghosh S 2013 Prediction of extreme rainfall event using weather pattern recognition and support vector machine classifier; Theor. Appl. Climatol. 114(3-4) 583-603.

Nikam V and Gupta K 2013 SVM-based model for shortterm rainfall forecasts at a local scale in the Mumbai urban area, India; J. Hydrol. Eng. 19(5) 1048-1052.

Phatak J and Hukku A 2015 Case of Greater Mumbai, In: Monographs of the International Conference on Water,
Megacities and Global Change; 1-4 December 2015 at UNESCO HQ, Paris, France, UNESCO, Paris, pp. 1-32.

Rajah K, O'Leary T, Turner A, Petrakis G, Leonard M and Westra S 2014 Changes to the temporal distribution of daily precipitation; Geophys. Res. Lett. 41(24) 88878894.

Rana A, Uvo C B, Bengtsson L and Sarthi P P 2012 Trend analysis for rainfall in Delhi and Mumbai, India; Clim. Dyn. 38 45-56.

Sen S, Vittal H, Singh T, Singh J and Karmakar S 2013 At-site design rainfall estimation with diagnostic check for nonstationarity: An application to Mumbai rainfall datasets; Hydro, IIT Madras, 4-6 December.

Roth M 2000 Review of atmospheric turbulence over cities; Quart. J. Roy. Meteorol. Soc. 126(564) 941-990.

Singh J, Vittal H, Singh T, Karmakar S and Ghosh S 2015 A framework for investigating the diagnostic trend in stationary and nonstationary flood frequency analyses under changing climate; J. Climate Change 1(1-2) 47-65.

St-Onge B A and Cavayas F 1997 Automated forest structure mapping from high resolution imagery based on directional semivariogram estimates; Remote Sens. Environ. 61(1) 82-95.

Sherly M A, Karmakar S, Chan T and Rau C 2015a Design rainfall framework using multivariate parametric-nonparametric approach; J. Hydrol. Eng. 21(1) 04015049.

Sherly M A, Karmakar S, Parthasarathy D, Chan T and Rau C 2015b Disaster vulnerability mapping for a densely populated coastal urban area: An application to Mumbai, India; Ann. Assoc. Am. Geogr. 105(6) 1198-1220.

Shyamala B and Bhadram C V V 2006 Impact of mesoscalesynoptic scale interactions on the Mumbai historical rain event during 26-27 July 2005; Curr. Sci. 91(12) 1649-1654.

Tobler W 1970 A computer movie simulating urban growth in the Detroit region; Econ. Geogr. 46(2) 234-240.

Vittal H, Singh J, Kumar P and Karmakar S 2015 A framework for multivariate data-based at-site flood frequency analysis: Essentiality of the conjugal application of parametric and nonparametric approaches; J. Hydrol. 525 658-675.

Zope P E, Eldho T I and Jothiprakash V 2015 Study of spatio-temporal varaitions of rainfall pattern in Mumbai city, India; J. Environ. Res. Develop. 6(2) 545-553. 